\title{
Myelin localization of peptidylarginine deiminases 2 and 4: comparison of PAD2 and PAD4 activities
}

\author{
Dorothy D Wood ${ }^{1}$, Cameron A Ackerley², Ben van den Brand ${ }^{1}$, Li Zhang ${ }^{1}$, Reinout Raijmakers³ \\ Fabrizio G Mastronardi ${ }^{1}$ and Mario A Moscarello ${ }^{1}$
}

An understanding of the structure and composition of the myelin sheath is essential to understand the pathogenesis of demyelinating diseases such as multiple sclerosis (MS). The presence of citrulline in myelin proteins in particular myelin basic protein (MBP) causes an important change in myelin structure, which destabilizes myelin. The peptidylarginine deiminases (PADs) are responsible for converting arginine in proteins to citrulline. Two of these, PAD2 and PAD4, were localized to the myelin sheath by immunogold electron microscopy. Deimination of MBP by the recombinant forms of these enzymes showed that it was extensive, that is, PAD2 deiminated 18 of 19 arginyl residues in MBP, whereas PAD4 deiminated 14 of 19 residues. In the absence of PAD2 (the PAD2-knockout mouse) PAD4 remained active with limited deimination of arginyl residues. In myelin isolated from patients with MS, the amounts of both PAD2 and PAD4 enzymes were increased compared with that in normals, and the citrullinated proteins were also increased. These data support the view that an increase in citrullinated proteins resulting from increased PAD2 and 4 is an important change in the pathogenesis of MS.

Laboratory Investigation (2008) 88, 354-364; doi:10.1038/labinvest.3700748; published online 28 January 2008

KEYWORDS: peptidylarginine deiminase; citrullinated myelin basic protein; myelin; multiple sclerosis; neurodegenerative disease

Peptidylarginine deiminases (PADs) are enzymes which deiminate arginyl residues in proteins. Five isozymes, termed PADs 1-4 and PAD6, are known, which have some tissue specificity, although PAD2 is widely distributed. ${ }^{1}$ It is the principal PAD enzyme in brain, where it has been shown to be responsible for the deimination of arginyl residues in myelin basic protein (MBP), a principal protein in myelin ${ }^{2}$ and a possible autoantigen in multiple sclerosis (MS). ${ }^{3,4}$ The presence of other PAD enzymes in myelin has not been reported. For all PADs, the deimination reaction involves the conversion of arginyl residues in proteins to citrulline and the formation of ammonia. ${ }^{5}$ The conversion of arginine to citrulline involves the loss of one positive charge from the protein for each arginine deiminated.

In earlier studies, we reported that MBP isolated from white matter from normal human brain could be fractionated into several components by column chromatography. One of these components, which accounted for $20 \%$ of all the MBP, contained six citrullinyl residues, the sites of which we determined by protein sequencing. ${ }^{6}$ More recently, the deimination has been shown to be more extensive by mass spectrometry with partial deimination of many arginines. ${ }^{7}$ The loss of six positive charges accounted for the chromatographic behavior on the cation-exchange column. This same fraction isolated from patients with MS accounted for $45 \%$ of the total MBP, and in a case of fulminating MS, it accounted for $80-90 \%$ of all the MBP. ${ }^{8}$ Instead of six arginyl residues in normal MBP, ${ }^{6} 18$ of 19 arginyl residues in the Marburg's MBP were deiminated. In a number of in vitro studies in protein-lipid interaction systems, we showed that this deiminated protein was unable to compact lipid bilayers, causing destabilization, which might be the mechanism of demyelination. ${ }^{9}$ Our recent studies have revealed that the deiminated MBP was more susceptible to proteolysis by myelin-associated proteases, ${ }^{10,11}$ and the citrullinated MBP was digested autocatalytically in vitro, releasing the immunodominant epitope in the absence of proteases. ${ }^{12}$ These studies have been reviewed recently. ${ }^{4}$ Although the contribution of PAD enzymes in the pathogenesis of MS is unclear at this time, the presence of large amounts of

\footnotetext{
${ }^{1}$ Molecular Structure and Function, The Hospital for Sick Children, Toronto, ON,

Canada; ${ }^{2}$ Department of Pathology, The Hospital for Sick Children, Toronto, ON, Canada and ${ }^{3}$ Department of Biomolecular Chemistry, Nijmegen Center for Molecular Life Sciences, Radboud University Nijmegen, Nijmegen, The Netherlands

Correspondence: Dr MA Moscarello, MD, PhD, Molecular Structure and Function, The Hospital for Sick Children, 555 University Avenue, Toronto, Ontario, Canada M5G 1X8. E-mail: mam@sickkids.ca
}

Received 17 October 2007; revised 03 December 2007; accepted 10 December 2007 
citrullinated MBP suggests a strong link between citrullinated MBP and peptidylarginine deiminases.

Since MBP is a major myelin protein and citrullinated MBP was localized in myelin by immunogold electron microscopy ${ }^{13}$ the localization of PAD2 in myelin was undertaken. Immunogold studies were carried out with an antiPAD2 antibody. The data demonstrate clearly that PAD2 is localized in myelin, in the vicinity of MBP its natural substrate. The number of gold particles in myelin from MS brain was increased threefold over normal, in agreement with a previous study in which we reported a threefold increase in the amount of PAD 2 by immunoblots. ${ }^{14}$ In a study of the deiminated sites, no restrictions were observed, that is, all arginyl residues except one were targets for deimination in aqueous media. Since citrullinated MBP is generated by PAD, these studies suggest that decreased PAD enzyme activity may be a therapeutic target with PAD-specific inhibitors, as suggested for rheumatoid arthritis. ${ }^{15,16}$

We extended our studies on PAD2 in myelin by studying a PAD2-knockout mouse to determine if citrullinated MBP could be formed in the absence of PAD2. We demonstrated that citrullinated MBP was present and was formed by the PAD4 enzyme. Immunogold localization of PAD4 showed it to differ from that of PAD2. PAD2 was found in clusters, whereas PAD4 was distributed as single particles in myelin and in axons. Nuclear labeling of PAD4 was a prominent feature. The presence of PAD4 in myelin was also confirmed by Western blot of myelin proteins isolated from PAD2 null mice.

\section{MATERIALS AND METHODS Materials}

$\alpha$ - $N$-benzoyl-L-arginine ethyl ester (BAEE), L-citrulline and calf thymus histone type IIA were purchased from Sigma Chemical Company (St Louis, MO, USA). MBP was prepared by the method of Cheifetz and Moscarello. ${ }^{17}$ The charge isomers were isolated on CM52 columns as described by us. ${ }^{6}$ Normal human brain was obtained from the Canadian Brain Tissue Bank. Normal white matter samples from brains of MS patients and white matter from non-neurological controls were obtained from the MS tissue bank at UCLA. Human recombinant PAD2 and PAD4 (EC 3.5-3.15) were prepared as described by Raijmakers $e t \mathrm{al}^{18}$ and supplied to us for this study. The normal mice used for this study were on the CD-1 background, and were housed in the Hospital for Sick Children Animal Care facility. These studies were approved by the Animal Care Committee at The Hospital for Sick Children. The brains from PAD2-null mice ${ }^{19}$ and normal controls were provided in a frozen condition from the Netherlands, and were obtained in accordance with approved animal protocols.

\section{Preparation of Myelin}

Myelin was prepared from normal-appearing white matter from brains of MS tissue and normal human white matter obtained from the brain tissue bank at UCLA, by the method of Cruz and Moscarello. ${ }^{20}$

\section{Antibodies}

Primary antibodies included anti-MBP monoclonal antibody from Chemicon (MAb348). The epitope for this antibody has been characterized by Groome et al. ${ }^{21}$ The polyclonal antibody to PAD isozymes ${ }^{1-4}$ was a gift from Dr H Takahara (Department of Applied Biological Resource Sciences, School of Agriculture, Ibaraki University, Ami-machi, Inashiki-gun, Ibaraki, Japan). It reacts with all the PAD enzymes because of the high degree of sequence homology at the C-terminus of these enzymes. ${ }^{22}$ The isotype-specific anti-PAD2 antibody was generated by immunization with two peptides comprising amino acids $3-18$ and $516-531$ of human PAD2. ${ }^{18,19}$ The PAD4 isotype-specific antibody was raised against peptides $180-194$ of human PAD4. ${ }^{18}$ The monoclonal anticitrulline antibody, MAbF95 $5^{23}$ was obtained from $\mathrm{Dr} \mathrm{A}$ Nicholas, Birmingham, Alabama.

\section{Immunogold Electron Microscopy}

Pellets of myelin isolated from white matter from normal individuals and normal-appearing white matter from patients with MS and optic nerves from normal CD-1 mice were fixed in $4 \%$ paraformaldehyde containing $0.1 \%$ glutaraldehyde in $0.1 \mathrm{M}$ phosphate buffer, $\mathrm{pH} 7.4$, for a minimum of $4 \mathrm{~h}$. Following a thorough rinse in phosphate buffer, samples were infused with $2-3 \mathrm{M}$ sucrose for several hours before freezing in liquid nitrogen. The sucrose-infused material was then mounted on aluminum ultramicrotomy pins, plunged frozen in liquid nitrogen and ultrathin cryosections were prepared with a cryo-ultramicrotome at $-95^{\circ} \mathrm{C}$ with a diamond knife. Sections were transferred to formvar nickel grids with a loop of molten sucrose and labeled using immunogold. Following blocking in PBS containing 0.15\% glycine and $0.5 \% \mathrm{BSA}$, the grids were rinsed with $\mathrm{PBS} / \mathrm{BSA}$ before incubation with a polyclonal antibody against PAD for $1 \mathrm{~h}$. The grids were then washed several times with PBS/BSA before incubation with either goat anti-rabbit $\operatorname{IgG}(10 \mathrm{~nm})$ for isolated myelin or $5 \mathrm{~nm}$ gold particles for murine optic nerve (Amersham Life Sciences, IL, USA), for an additional hour. In double-labeling experiments, samples were rinsed thoroughly with PBS/BSA and then incubated with MAb26, ${ }^{21}$ a monoclonal antibody that recognizes MBP. Again, the samples were rinsed thoroughly in PBS/BSA and incubated with $10 \mathrm{~nm}$ gold goat anti-murine complexes (Amersham Life Sciences). After a thorough rinsing in PBS and distilled water, sections were stabilized in a thin film of methylcellulose containing $0.2 \%$ uranyl acetate. Controls included the omission of either primary antibody or antibody gold complexes. All of the grids were then examined in JEOL JEM 1230 transmission electron microscope (JEOL USA; Peabody, MA, USA) and images were acquired with a digital camera (AMT Corp, Danvers, MA, USA). Gold particle densities were calculated in particles $/ \mu \mathrm{m}^{2}$ of myelin. Images acquired with the 
camera were exported into an image analysis program (SCION Image, Frederick, MD, USA) and 28 images from normal and MS were analyzed. Data were expressed as mean and standard error. Significance was determined using Student's $t$-test.

\section{Immunoslot Blot for PAD2 and PAD4 in Myelin Fraction of CD-1 Mice}

CD-1 mouse brains were homogenized in $0.25 \mathrm{M}$ sucrose and separated on sucrose gradient of $0.25,0.88,1$ and $1.2 \mathrm{M}$ sucrose by centrifuging for $1 \mathrm{~h}$ at $28000 \mathrm{r} . \mathrm{p} . \mathrm{m}$. The interphase between 0.25 and $0.88 \mathrm{M}$ contained the myelin fraction, which was collected and washed three times. Samples were diluted to $0.1 \mathrm{mg} / \mathrm{ml}$ in $3 \mathrm{M}$ urea/PBS and $10 \mu \mathrm{g}$ protein was applied onto nitrocellulose membrane using Bio-Dot SF Microfiltration Apparatus. After blocking for $1 \mathrm{~h}$ in $5 \%$ milk in Tris-buffered saline and $0.05 \%$ Tween 20 (TBS/T), membranes were incubated for $1.5 \mathrm{~h}$ at room temperature with polyclonal anti-PAD2 (1:1000), polyclonal anti-PAD4 (1:1000) or polyclonal anti-actin antibodies (1:200) (Sigma) diluted in 5\% milk in TBS/T. Subsequently, membranes were incubated with HRP-conjugated anti-rabbit (1:5000) (BioRad) antibody diluted in 5\% milk in TBS/T for $1 \mathrm{~h}$ at room temperature, and then visualized with ECL (GE Healthcare).

Numbers of pixels on film were measured with the Image SXM image analysis software, using a Macintosh (Apple Inc., Cupertino, CA, USA) computer with OSX version 10.4.10. The average of two measurements per sample was used to calculate the PAD-protein/actin ratio. Student's $t$-test was used to determine significance between the PAD2 and PAD4 measurements.

\section{PAD Enzyme Assays}

PAD activity was measured with recombinant PAD2 and PAD4, using benzoylarginine ethyl ester (BAEE) as substrate, as previously described. ${ }^{2} \mathrm{MBP}$ was deiminated by PAD2 and PAD4 in separate experiments using similar conditions. For the mass spectrometry experiments, MBP was deiminated for $2 \mathrm{~h}$ to ensure complete deimination.

When BAEE was used as substrate, varying concentrations of BAEE were incubated in $0.1 \mathrm{M} \mathrm{CaCl}_{2}, 1.0 \mathrm{M}$ HEPES buffer $\mathrm{pH}$ 7.6, $0.08 \mathrm{M}$ DTT and $1 \mu \mathrm{l}$ of enzyme solution containing $2.6 \mu \mathrm{g}$ PAD2 or $2.2 \mu \mathrm{g}$ PAD4. The reaction was stopped with $100 \mu \mathrm{l}$ of $5 \mathrm{~N}$ perchloric acid. Each sample was centrifuged at $4^{\circ} \mathrm{C}$ for $3 \mathrm{~min}$ at 1500 r.p.m. in a Hettich (Tuttingen, Germany) tabletop centrifuge. Aliquots of $400 \mu$ l were used in the citrulline assays. The aliquots were mixed with $1 \mathrm{ml}$ of reagent $\mathrm{B}(10 \%$ antipyrine $+2.5 \%$ ferric ammonium sulfate, $3.5 \mathrm{~N}$ sulfuric acid and $3.5 \mathrm{~N}$ orthophosphoric acid. Reagent A $(0.5 \mathrm{ml})$, containing $0.5 \%$ diacetylmonoxime and $15 \%$ sodium chloride, was added and the mixture was vortexed before boiling the sample for $15 \mathrm{~min}$ in a water bath. The samples were cooled on ice and absorbance was read at $464 \mathrm{~nm}$. When MBP was used as substrate, component 1
(C-1 the least modified of the MBP components) was added in amounts varying from 0 to $250 \mu \mathrm{g}$ of protein.

\section{Preparation of MBP from Mouse Myelin}

MBP was extracted from myelin with $0.2 \mathrm{~N}$ sulfuric acid and centrifuged for $1 \mathrm{~h}$ at $4^{\circ} \mathrm{C}$. The supernatant was removed and dialyzed against water overnight. Protein assays were carried out by the method of Peterson. ${ }^{24}$

\section{Immunodetection}

Myelin proteins were resolved through a $12.5 \%$. SDS-polyacrylamide gel by electrophoresis and western blotted onto nitrocellulose membrane. Non-protein sites on the nitrocellulose membranes were blocked with $5 \%$ milk in TBS/ $0.05 \%$ Tween 20 and subsequently incubated with the following primary antibodies diluted in blocking buffer: anti-PAD4 (1:250), F95 (1:50) and anti-MBP (1:10 000) for $1 \mathrm{~h}$ at room temperature. The following secondary antibodies were diluted in blocking buffer: anti-rabbit IgG HRP-conjugated (1:5000) for antibody anti-PAD4, anti-mouse IgM HRP-conjugated antibody for F95 (1:50) and anti-mouse IgG HRP-conjugated antibody for anti-MBP (1:10 000), and incubation was performed for $1 \mathrm{~h}$ at room temperature. Antibodies were visualized with ECL (GE Healthcare).

For immunoslot blot analysis, the number of pixels on film were measured with Image SXM. The average from three measurements per sample was used to calculate citrulline/ MBP ratios. A Student's $t$-test was used to determine significance.

\section{Preparation of Lipid Vesicles}

Egg phosphatidylcholine (PC) and bovine brain phosphatidylserine (PS) were purchased from Avanti (Birmingham, AL, USA) as dry powders. For preparation of the vesicles, the lipids were dissolved in chloroform at a concentration of $20 \mathrm{mg} / \mathrm{ml}$ (PC) and $10 \mathrm{mg} / \mathrm{ml}$ (PS), and stored under nitrogen at $-20^{\circ} \mathrm{C} .{ }^{6}$ Aliquots of the lipids generating a mixture of 92.2\% PC and 7.8\% PS were transferred to autoclavable tubes and the chloroform was evaporated under a stream of nitrogen and further dried by lyophilizing for $10 \mathrm{~min}$. The lipids were suspended in $1 \mathrm{ml}$ of HEPES buffer, $\mathrm{pH}$ 7.6, containing $0.1 \mathrm{M} \mathrm{CaCl}_{2}$ and $0.08 \mathrm{M} \mathrm{DTT}$, and then sonicated in a water bath at room temperature until clarified (approximately $30 \mathrm{~min}$ ). The vesicles were centrifuged at 15000 r.p.m. for $15 \mathrm{~min}$ in Hettich centrifuge. The lipid vesicles were suspended in $490 \mu \mathrm{l}$ of HEPES buffer and the MBP was added followed by $10 \mu \mathrm{l}$ of PAD2 or PAD4, and the mixture was incubated at $52^{\circ} \mathrm{C}$ for $2 \mathrm{~h}$. After incubation, ether was added to remove the lipid and the insoluble material was taken up in water and dialyzed for 20 min using three changes of water. The retentates were lyophilized.

\section{Mass Spectrometry}

Molecular masses of intact human MBP (component C-1) and its citrullinated forms were measured with a QSTAR XL 
electrospray ionization QTOF mass spectrometer (Applied Biosystems/MDS Sciex, Concord, ON, Canada) in positive ion mode. Samples of $5 \mu \mathrm{g}$ each were dissolved in a solution of acetonitrile and deionized water $(1: 1, \mathrm{v} / \mathrm{v})$ containing $0.2 \%$ of formic acid at a concentration of $10 \mathrm{pmol} / \mu \mathrm{l}$. Samples consisting $2 \mu \mathrm{l}$ of each were injected using an HPLC system (Waters, Milford, MA, USA) and carried over to the nanospray source by a mobile phase of $50 \%$ acetonitrile in deionized water containing $0.2 \%$ of formic acid. The flow rate was kept at $6 \mu \mathrm{l} / \mathrm{min}$ and the capillary voltage was maintained at $3000 \mathrm{eV}$. The mass spectra obtained were deconvoluted using the Bayesian Protein reconstruct script, which comes with the ABI BioAnalyst 1.1 software.

\section{Protein Sequence Determination}

MBP samples ( $5 \mu \mathrm{g}$ ) were digested in solution using $0.05 \mu \mathrm{g}$ of trypsin in $25 \mathrm{mM}$ ammonium bicarbonate solution in a total volume of $50 \mu \mathrm{l}$. After overnight incubation at $37^{\circ} \mathrm{C}$, the peptide solution was lyophilized by SpeedVac centrifugation and resuspended in $20 \mu \mathrm{l} 0.1 \%$ trifluoroacetic acid (TFA). Each sample consisting of $1 \mu \mathrm{l}$ solution was mixed with $1 \mu \mathrm{l}$ of 2,5-dihydroxybenzoic acid $(120 \mathrm{mg} / \mathrm{ml}$ in acetonitrile/ $\left.\mathrm{H}_{2} \mathrm{O}, 1: 1, \mathrm{v} / \mathrm{v}\right)$ and spotted on the target plate for MALDIQTOF MS analysis. Peptide mass measurements were performed with a QSTAR XL MALDI-QTOF mass spectrometer (Applied Biosystems/MDS Sciex). The instrument was equipped with a UV nitrogen laser $(337 \mathrm{~nm})$ and the acceleration voltage was $4 \mathrm{kV}$. Nitrogen and argon were used as curtain and collision gases, respectively.

LC/MS/MS experiments were performed with a QSTAR XL electrospray ionization QTOF mass spectrometer (Applied Biosystems/MDS Sciex) coupled with an Agilent 1100 NanoLC system (Santa Clara, CA, USA). Samples ( $5 \mu \mathrm{l}$ ) were first loaded onto a pre-column $(100 \mu \mathrm{m}$ i.d. $\times 5 \mathrm{~cm})$ and then eluted to an analytical column $(75 \mu \mathrm{m}$ i.d. $\times 10 \mathrm{~cm})$ for further separation. Both columns were home made and packed with Pursuit C18 ( $5 \mu \mathrm{m}$ particle size, $200 \AA$ pore size; Varian Inc., Palo Alto, CA, USA). The mobile phase was composed of solutions $\mathrm{A}$ and $\mathrm{B}$, where $\mathrm{A}$ was $2 \%$ acetonitrile in water and $\mathrm{B}$ was $90 \%$ acetonitrile in water, each containing $0.1 \%$ formic acid and $0.02 \%$ TFA. The gradient started at $0 \% \mathrm{~B}$ and ramped to $100 \% \mathrm{~B}$ in $65 \mathrm{~min}$. Flow rate was set at $0.2 \mu \mathrm{l} /$ min. MS and MS/MS experiments were performed using information-dependent acquisition with each cycle time of $10 \mathrm{~s}$ (1-s MS scan followed by three $3 \mathrm{~s}$ MS/MS scans). The data set was converted into a peak list file called Mascot Generic File (MGF) using the Mascot script, which comes with the Analyst QS 1.1 software. The MGF files were then used to search against the human MBP FASTA sequence database, using our in-house MASCOT search engine. Protein N-terminal acetylation, arginine methylation, dimethylation, arginine citrullination and methionine oxidation were set as variable modifications in the search. Peptide mass tolerance and MS/MS tolerance was set to $0.3 \mathrm{Da}$.

\section{RESULTS}

\section{Localization of PAD in Myelin}

To demonstrate the presence of PAD in myelin, cryosections of myelin isolated from normal and MS white matter were labeled with a polyclonal PAD antibody (which recognizes all PAD isoforms) as described in Materials and Methods. Representative sections are shown in Figure 1a and b. Gold particles were found in the myelin sheath isolated from normal human white matter (Figure 1a). An increased number of gold particles were observed in myelin isolated from MS normal-appearing white matter (Figure 1b). The increase in gold particles was quantitated by obtaining particle densities (particles $/ \mu \mathrm{m}^{2}$ of myelin). These are shown in Table 1 . The number of particles/ $\mu \mathrm{m}^{2}$ was increased approximately threefold in the MS samples, showing an approximately threefold increase in PAD enzyme in white matter from MS tissue. This is consistent with our immunoslot blot measurements showing a threefold increase in the amount of PAD2 enzyme in normal-appearing white matter from MS tissue. ${ }^{14}$

\section{Localization of PAD in Murine White Matter}

Since the myelin shown in Figure 1 was prepared from normal-appearing white matter obtained at autopsy, we examined optic nerve from normal CD-1 mice to examine gold labeling of myelin in situ. These are shown in Figure $2 a-c$ for PAD2 and Figure 3a-c for PAD4. PAD2 labeling was found in the oligodendrocyte (Figure 2a) and in the myelin (upper right-hand corner). The large particles in this figure represent MBP labeling, whereas the small particles represent PAD2 labeling. Although PAD2 labeling was distributed throughout the cell, much of the labeling was found in clusters, suggestive of a vesicular localization. PAD2 labeling was found in the axon (Figure 2b) largely in clusters (arrows), and in the periaxonal region (arrowheads). Clusters of PAD2-labeled gold particles were also found in myelin (Figure 2c, arrowheads).

Immunogold labeling for PAD4 is shown in Figure 3a-c. PAD4 labeling was found in the oligodendrocyte cytoplasm (Figure 3a) and in the nucleus associated with chromatin. In the axon, particles were associated with intermediate filaments (Figure 3b). Gold labeling of intermediate filaments, as well as myelin labeling, is also shown in Figure 3c. Much of the myelin labeling was in the periaxonal space. The gold labeling for PAD2 was in clusters, whereas that for PAD4 was generally observed as single particles. Control sections were incubated with either secondary gold-conjugated antibody alone (Supplementary Figure 1A), or with primary anti-PAD2 antibody preadsorbed with PAD2 protein (Supplementary Figure 1B).

\section{Quantitation of PAD2 and PAD4 in Isolated Myelin}

To determine the amount of PAD2 and PAD4 in myelin isolated from normal and MS white matter, we performed immunoslot blots with specific PAD2 and PAD4 antibodies 

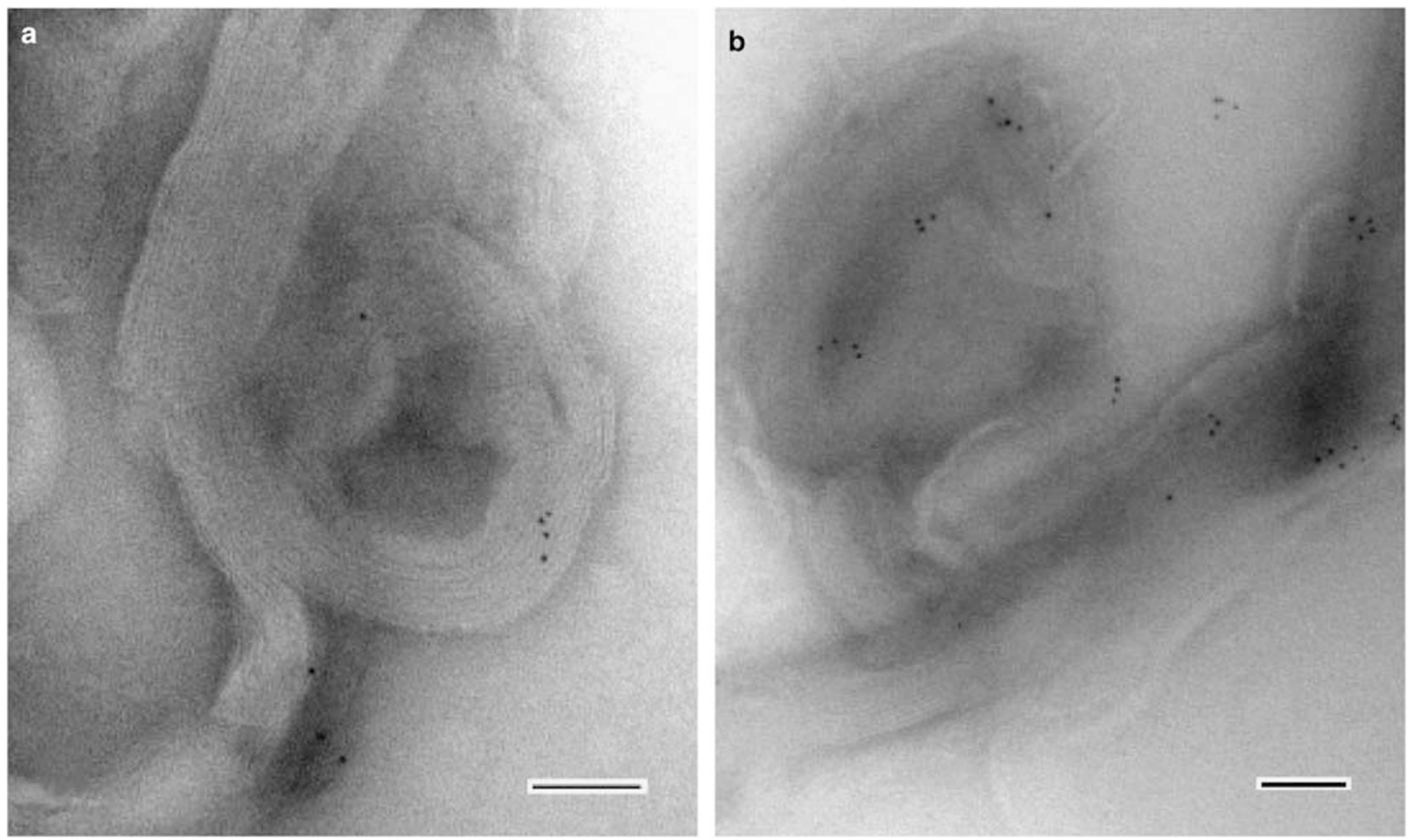

Figure 1 Gold labeling of PAD in isolated myelin with a pan PAD antibody. (a) Normal myelin. Gold particles are randomly distributed. Bars $=2 \mu \mathrm{m}$. (b) Myelin from MS white matter showing an increase in gold particles. Bars $=2 \mu \mathrm{m}$.

Table 1 PAD localization in myelin

\begin{tabular}{lc}
\hline & Gold particle density (particles $/ \mu \mathrm{m}^{2}$ myelin) \\
\hline Normal & Multiple sclerosis \\
\hline $8.2 \pm 2.4$ & $26 \pm 7.8$ \\
\hline
\end{tabular}

$n=28$ for each of normal and MS tissue.

$P<0.001$.

(Figure 4). We also measured the amount of citrulline with anti-citrulline antibody F95. The amount of citrulline present in the MS samples was increased compared with that in normals, although there was considerable variation from patient to patient. Less variation was observed in the normals. Levels of both PAD2 and PAD4 were increased significantly in the MS myelin fractions.

\section{PAD Activity Assays}

(a) BAEE as substrate: We measured the activity of PAD2 with benzoylarginine ethyl ester, the synthetic substrate, as a function of substrate concentration (Figure 5a). With PAD2, the specific activity rose sharply at $0.68 \times 10^{2} \mu \mathrm{g}$
BAEE then plateaued. With PAD4, the specific activity increased more gradually and was less than that of PAD2.

(b) MBP as a substrate: Although BAEE is a useful synthetic substrate for the PAD enzymes, we are the first to report that MBP, the natural substrate in brain is deiminated in vitro. The specific activities of recombinant PAD2 and PAD4 with MBP as substrate are shown in Figure 5b. With this natural substrate, PAD4 showed greater activity than PAD2 at all concentrations of MBP. Neither enzyme reached maximum activity that is, $\mathrm{V}_{\text {max }}$. Since both enzymes deiminated MBP, we compared the deiminated arginyl sites to determine if there were any preferential sites.

\section{Identification of Arginyl Residues Deiminated}

The mass spectrum of the deiminated MBP, component- 1 (C-1), is shown in Figure 6a. The non-citrullinated protein is shown with a mass of 18501.30 atomic mass units (amu), as reported earlier by $\mathrm{us}^{25}$ for $\mathrm{C}-1$ component containing an N-terminal acetyl group. The citrullinated form of the protein had a mass of $18517.40 \mathrm{amu}$. Monomethylated and citrullinated C-1 are shown at the mass of $18531.00 \mathrm{amu}$, and the dimethylated form is shown at $18544.90 \mathrm{amu}$. The mass difference between the uncitrullinated $18501.30 \mathrm{amu}$ and the citrullinated form $18577.40 \mathrm{amu}$ represents a mass difference of 16.1, suggesting 16 completely deiminated residues. 

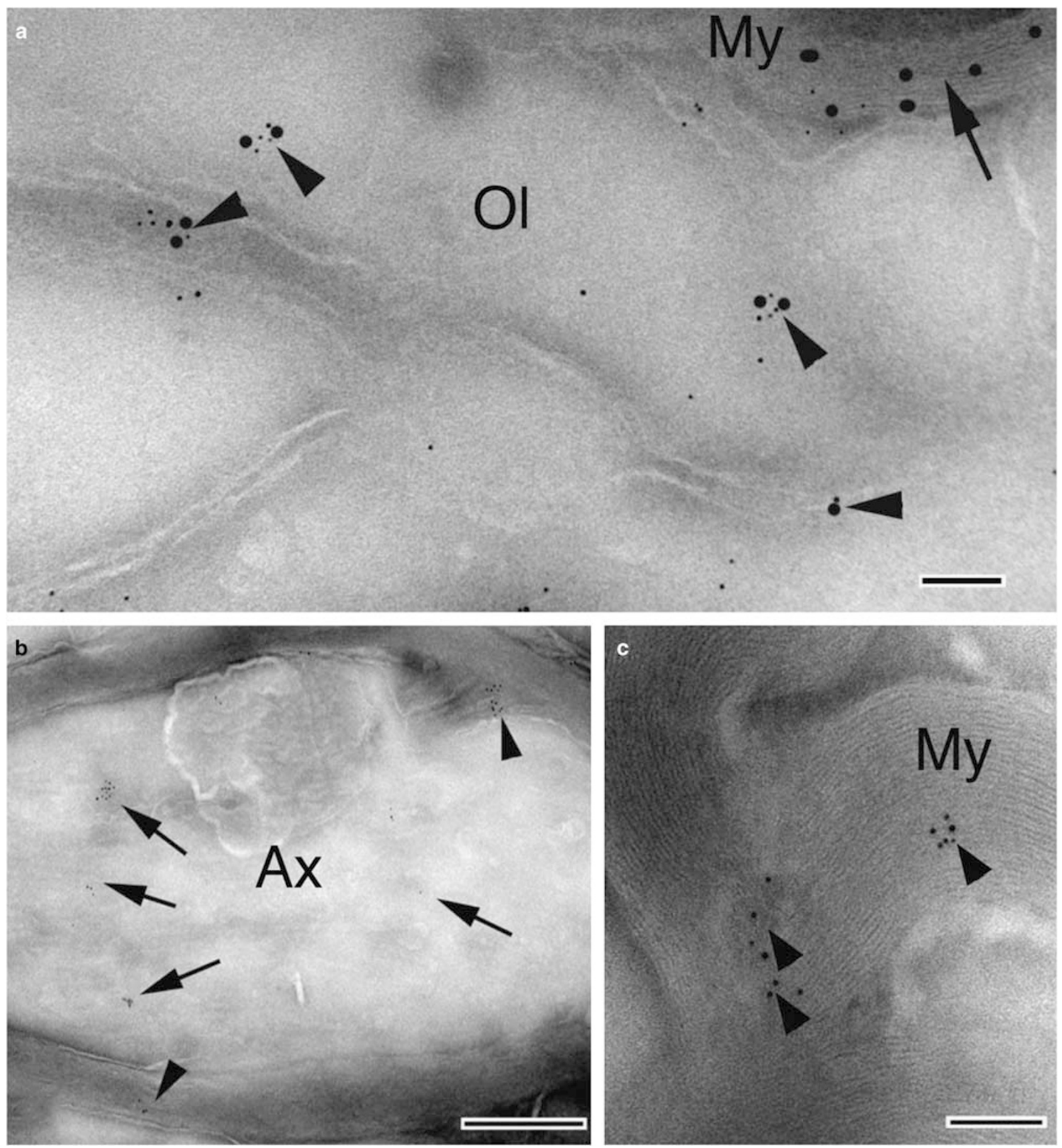

Figure 2 Immunogold electron microscopy of normal mouse optic nerve, with anti PAD2 antibody. (a) Oligodendrocyte showing PAD2 labeling (small particles) and MBP labeling (large particles). Ol, oligodendrocyte; My, myelin. Bars $=2 \mu \mathrm{m}$. (b) PAD2 labeling in the axon (arrows) and periaxonal distribution (arrowhead). Ax, axon. Bars $=2 \mu \mathrm{m}$. (c) PAD2 labeling in myelin showing distribution in clusters (arrowheads). My, myelin. Bars $=2 \mu \mathrm{m}$.

Since we found 18 of 19 arginyl residues to be deiminated (see below), a small amount of non-deiminated arginyl residue accounted for the overall mass change of $16 \mathrm{amu}$. In order to determine the arginyl residues deiminated in MBP, the protein was isolated from the reaction mixture, digested with trypsin and the peptides were analyzed by mass spectrometry as described in Materials and Methods.
The arginyl residues converted to citrulline were determined by fragmentation analysis. The entire sequence of MBP showing the deiminated sites is shown in Figure $6 \mathrm{~b}$ for PAD2 and PAD4 reactions. The underlined arginines (R; Figure 6b) were deiminated by the PAD2 reaction, while the asterisks represent arginines deiminated in the PAD4 reaction. 

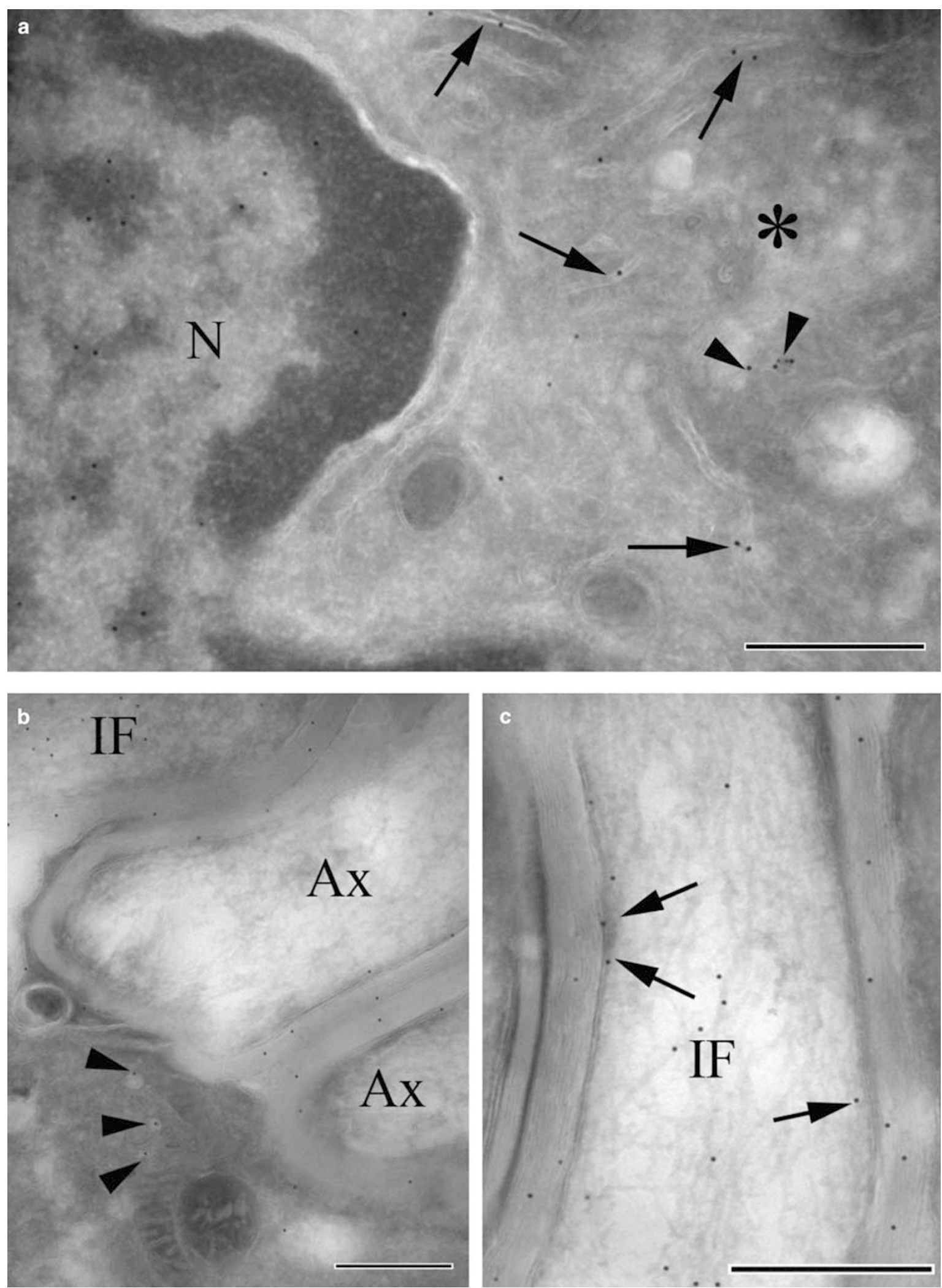

Figure 3 Immunogold electron microscopy of mouse optic nerve using anti-PAD4 antibody. (a) Oligodendrocyte showing PAD4 labeling (arrows and arrowheads) in the cytoplasm (asterisk) and nuclear labeling associated with chromatin. $\mathrm{N}$, nucleus. (b) Myelin labeling distributed as single particles (arrowheads). Ax, axon; IF, intermediate filaments. (c) Axonal labeling, axolema labeling (arrows) and intermediate filaments within the axon and myelin labeling. My, myelin; IF, intermediate filaments. Bars $=2 \mu \mathrm{m}$. 


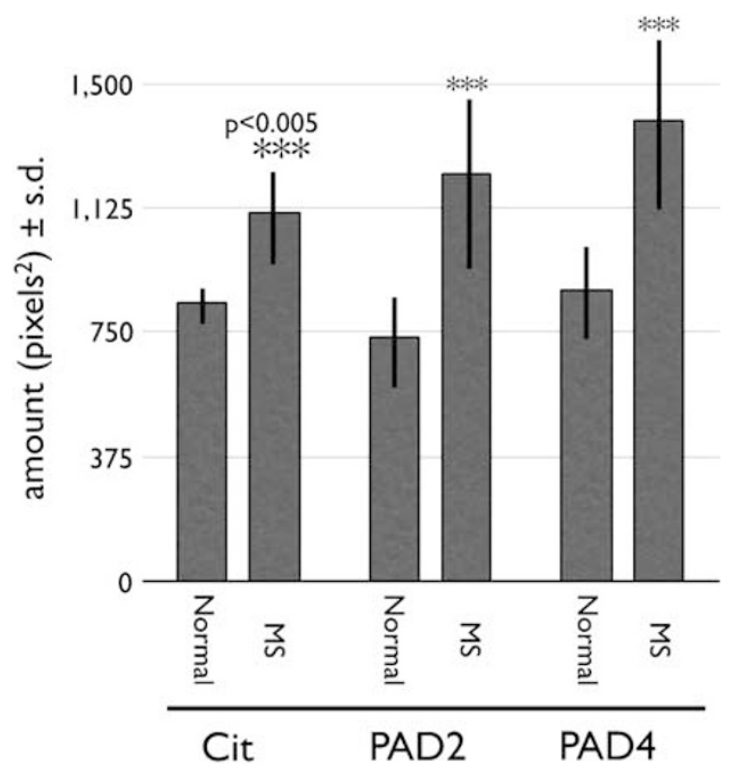

Figure 4 Immunoslot blot of solubilized myelin represented as a bar diagram showing reactivity to PAD2 and PAD4. Slot blots were probed with anti-citrulline antibody, F95, anti-PAD2 antibody and anti-PAD4 antibody. MS, multiple sclerosis; $n=6$ normal and 7 MS individuals. Representative slot blots are shown in Supplementary Figure $2 .{ }^{* *}=$ significant difference.

Several interesting conclusions arise from the data. It can be seen that most of the arginyl residues were deiminated by both PAD2 and PAD4, although PAD2 deiminated more sites than PAD4, for example, PAD2 deiminated 18 of 19 arginyl residues, whereas PAD4 deiminated 14 of 19 residues. Three of the sites not deiminated by PAD4 were in the N-terminal portion of the molecule (R5, R9 and R43), suggesting that structural factors either primary or secondary may be involved. In an earlier report, deimination of arginyl residues in trichohyalin adjacent to glutamic acid were only slightly modified, showing that amino-acid sequence influences PAD activity. ${ }^{26}$ Although many sites were deiminated to some extent, none was completely deiminated. This can be seen from the intensity of the peaks for the different peptides, which varied considerably (Supplementary data). The GRG site, which contains $\mathrm{R}^{107}$, the major methylated $\mathrm{R}$, is monoor dimethylated, but is also deiminated in those MBP molecules that are not methylated at this site. Since mass spectrometry of the protein after $2 \mathrm{~h}$ in the presence of either PAD2 or PAD4 revealed that both mono- and dimethylated arginines remained (Figure 6a), it suggested that deimination $^{5,27}$ of the methylated arginine did not occur. ${ }^{28-30}$ Consistent with our data, Raijmakers et $a l^{31}$ showed that the human, mouse and rabbit PAD enzymes were not able to 'reverse' the methylation of arginine residues by converting monomethylated arginine into citrulline in synthetic peptides. These authors showed that the human and mouse PAD enzymes can only convert non-methylated peptidylarginine into peptidylcitrulline in vitro. Our data support this conclusion.
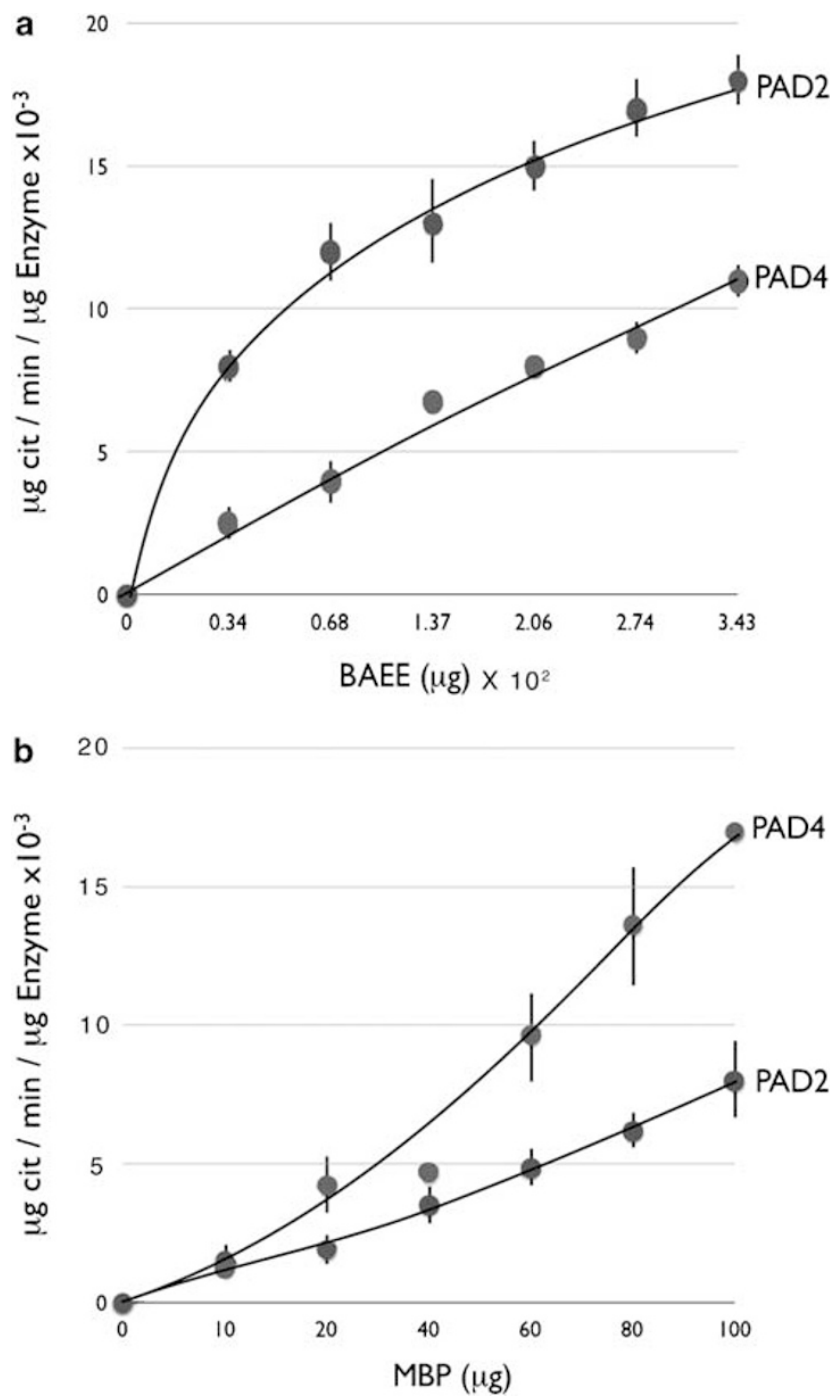

Figure 5 Velocity-substrate relationship of recombinant PAD2 and PAD4. (a) BAEE substrate $\left(\mu \mathrm{g} \mathrm{cit} / \mathrm{min} / \mu \mathrm{g}\right.$ enzyme $\left.\times 10^{-3}\right)$. (b) MBP substrate $\left(\mu \mathrm{g} \mathrm{cit} / \mathrm{min} / \mu \mathrm{g}\right.$ enzyme $\left.\times 10^{-3}\right)$.

\section{PAD4 and Citrullinated Proteins from Myelin of PAD2-Knockout Mice}

By western blot we were unable to detect PAD2 in solubilized myelin prepared from PAD2-null mouse brain. However, western blots with antibody to PAD4 showed good immunoreactivity (Figure 7), in agreement with the immunogold labeling (Figure 2), and the amount was similar to that found in the wild-type mice. To establish that MBP isolated from myelin of knockout mice was citrullinated, we isolated the acid-soluble MBP fraction from myelin, digested it with trypsin and subjected the digest to mass spectrometric analysis. In MBP from normal mouse myelin, we identified seven peptides in which arginine was deiminated. In the PAD2-knockout, we identified three citrullinated peptides, two of which represented the mono- and dimethylated arginyl residues in the GRG sequence. The third peptide 


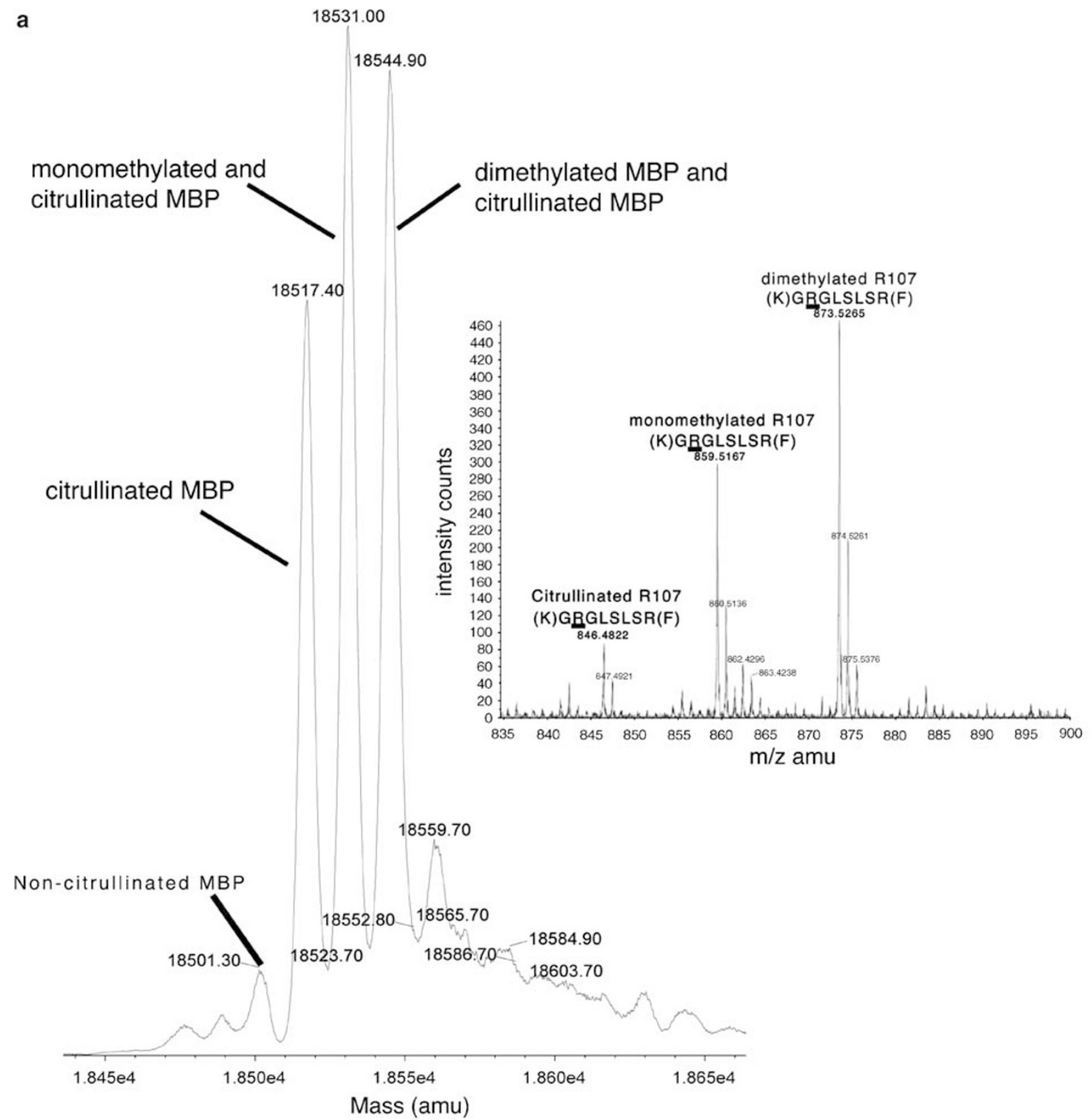

b

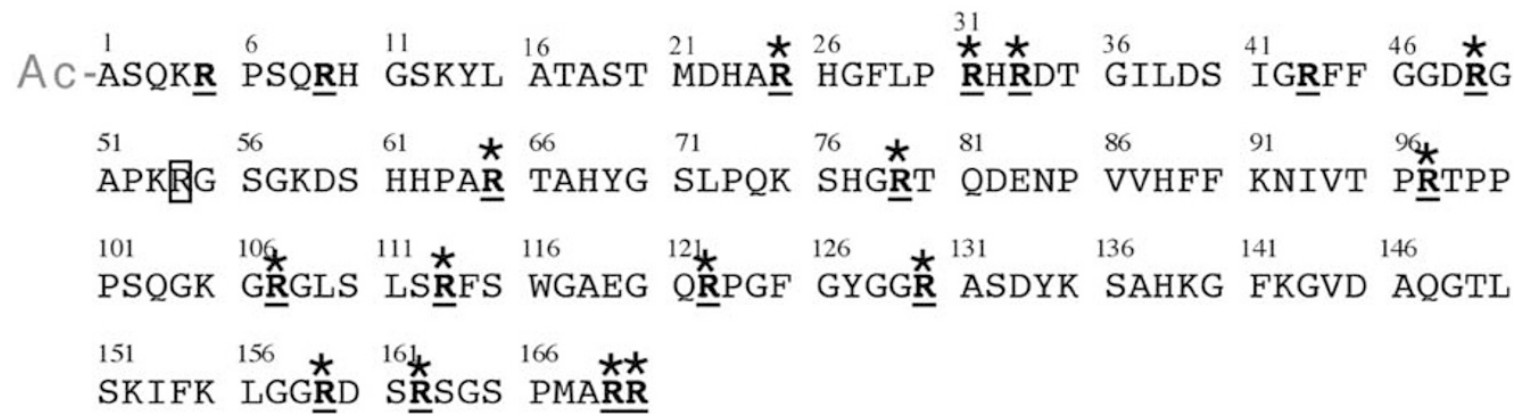

Figure 6 (a) Mass spectrogram showing the non-citrullinated C-1 MBP (18 501.30 amu), mono-methylated and citrullinated (18531.00 amu), dimethylated and citrullinated (18544.90 amu) forms of MBP. The inset shows the tryptic peptide GRGLSLSR, which contains dimethylated, mono-methylated and citrullinated R107, as determined by tandem mass spectrometric sequence of the fragmented peptide. (b) The sequence of MBP in single-letter code. The underlined $\mathrm{R}$ represents arginyl residues deiminated by PAD2. The asterisks $\left({ }^{*} \mathrm{R}\right)$ represent arginyl residues deiminated by PAD4. The boxed arginine (R54) represents the arginyl residue not deiminated by either enzyme. Ac- represents the acetylated $\mathrm{N}$-terminus. 
PAD2

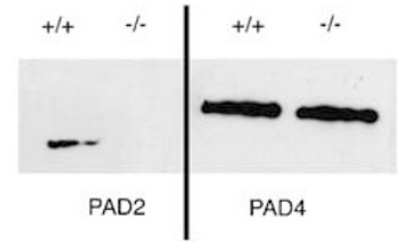

Figure 7 Western blot of myelin proteins with anti-PAD2 and anti-PAD4 antibodies in both PAD2 normal $(+/+)$ and PAD2-null $(-/-)$ mice.

contained the triproline sequence. This latter peptide was not deiminated in MBP digest from normal. These data demonstrate clearly that deimination occurs in the PAD2 knockout mouse and is probably due to the activity of PAD4. In addition to MBP several other proteins were found to be citrullinated in this MBP fraction. These included cyclic nucleotide phosphodiesterase and myelin-associated glycoprotein. Although the PAD2 enzyme is not present in the myelin isolated from the knockout mice, deimination still occurs.

\section{Deimination in Lipid Vesicles}

From the above results it can be concluded that specificity of PAD2 or PAD4 is not related to the amino-acid residues in the vicinity of the arginyl residues. Since MBP occurs naturally in a lipid environment, the effect of lipid on deimination was studied. For this purpose, we bound MBP C-1 to lipid vesicles consisting of $7.8 \%$ PS and $92.2 \%$ PC. Under these conditions, all of the MBP was bound to the vesicles.

When PAD2 was added to these vesicles, almost all arginyl residues were deiminated similar to the deimination of MBP in aqueous solution (see above). When PAD4 was used, most of the arginyl residues were deiminated as in aqueous solution. However, $\mathrm{R}^{5}$ and $\mathrm{R}^{9}$, which were not deiminated in aqueous solution, were deiminated when the MBP was bound to lipid vesicles. Interestingly, arginyl residues in the C-terminal 40 residues were not deiminated in contrast to these residues, when the protein was in aqueous solution. The reason for these differences is not understood at this time, but these data are suggestive that residues not deiminated by PAD4 may be partially buried into the lipid bilayer.

\section{DISCUSSION}

In our scheme of the pathogenesis of MS, we have shown that MBP from MS white matter contains an increased amount of citrullinated MBP, compared with MBP from normal white matter. ${ }^{6,832}$ With each arginine deiminated, one positive charge is lost from MBP, which compromises its ability to interact with phospholipids of the myelin sheath, resulting in less compact myelin being more easily degraded. These observations have led us to postulate that citrullinated MBP represents an important component in the pathogenesis of MS. ${ }^{4}$

The mechanism by which arginine is converted to citrulline in proteins involves a family of enzymes, the peptidy- larginine deiminases, of which five isoforms are known. ${ }^{1}$ Although they are widely distributed, PAD2 is the predominant brain enzyme, but PAD4 is also present, as we have shown previously ${ }^{14}$ and in this paper. In order to understand the important role of PAD2 in deimination of MBP in demyelinating disease, we have performed immunoelectron microscopy on intact mouse optic nerve with anti-PAD2 antibody, to localize it in the myelin sheath. We have shown that PAD2 is present in intact optic nerve myelin. It is found in clusters suggestive of vesicular localization. Although these clusters of PAD2 were found throughout the sections, many were localized in the periaxonal regions. Deimination of MBP at these sites may cause local destabilization of myelin, resulting in the patchy degeneration characteristic of MS. These studies are suggestive of an explanation for the morphological observation that the most distal tip of the oligodendrocyte (periaxonal) degrades first as an early event in apoptosis of oligodendrocytes in MS. ${ }^{33}$

A novel mechanism of demyelination is suggested by these data, that is, myelin degradation can begin in periaxonal region, where the myelin sheath contacts the axon. This is basically different from the autoimmune hypothesis in which sensitized cells attack the myelin sheath from the outside surface of myelin. In a recent study, we have shown that the promoter of the PAD2 gene was hypomethylated on the CG sequences due to the over-activity of a DNA demethylase. ${ }^{34}$ In the present work, we showed an increase in the number of PAD-labeled gold particles in myelin in MS. Therefore, upregulation of PAD2 by promoter hypomethylation and periaxonal localization with MBP may be prerequisites for myelin breakdown in a patchy distribution. In combination with myelin-associated proteases and the presence of PAD enzymes, the necessary enzymatic machinery is located in myelin to carry out the degradation of myelin components, leading to demyelination and activation of the immune response by release of proteolytic fragments of myelin proteins.

The presence of PAD4 in myelin represents a novel, but unexplained, observation. PAD4 contains a nuclear localization signal in its amino-acid sequence, which presumably targets PAD4 to the nucleus, as demonstrated in the Figure 3 electron micrograph in which the nucleus of the oligodendrocyte was labeled with gold particles. In myelin, the gold particles were distributed as single particles and not in clusters like PAD2. Its presence in myelin cannot be explained at this time. Regulation of these deimination reactions in myelin is essential for the maintenance of myelin stability. Our data from the PAD2-knockout mouse show that deimination of MBP is still possible in the total absence of the PAD2 gene, and is suggestive of the importance of PAD activity in myelin stability.

Supplementary Information accompanies the paper on the Laboratory Investigation website (http://www.laboratoryinvestigation.org) 


\section{ACKNOWLEDGEMENTS}

We gratefully acknowledge the support by Prinses Beatrix Fonds to BvB. RR was funded by the Dutch Technology Foundation through grant 790.35.898. We thank Dr Brian Werneburg (Boehringer Ingelheim Ridgefield, USA) for supplying PAD2-knockout mouse tissue samples. We are also grateful for the technical assistance provided by Mrs Teresa Miani, Ms Aina Tilups and Mr Howard Rosenberg in the Division of Pathology at The Hospital for Sick Children, Toronto. We thank both the Canadian Brain bank and Drs RM Nagra and WW Tourtellotte for providing normal and MS brain samples from the Human Brain and Spinal Fluid Resource Center's, VA West Los Angeles Healthcare Center, Los Angeles, CA 90073, which is sponsored by NINDS/NIMH, National Multiple Sclerosis Society (USA), and the Department of Veterans Affairs. This work was supported by Canadian Institute of Health Research (CIHR) grant to MAM and Multiple Sclerosis Society of Canada (MSSC) grant to MAM and FGM.

1. Vossenaar ER, Zendman AJ, van Venrooij WJ, et al. PAD, a growing family of citrullinating enzymes: genes, features and involvement in disease. Bioessays 2003;25:1106-1118.

2. Lamensa JW, Moscarello MA. Deimination of human myelin basic protein by a peptidylarginine deiminase from bovine brain. J Neurochem 1993;61:987-996.

3. Mastronardi FG, Moscarello MA. Molecules affecting myelin stability: a novel hypothesis regarding the pathogenesis of multiple sclerosis. J Neurosci Res 2005:80:301-308.

4. Moscarello MA, Mastronardi FG, Wood DD. The role of citrullinated proteins suggests a novel mechanism in the pathogenesis of multiple sclerosis. Neurochem Res 2007;32:251-256.

5. Kearney $\mathrm{PL}$, Bhatia $\mathrm{M}$, Jones $\mathrm{NG}$, et al. Kinetic characterization of protein arginine deiminase 4: a transcriptional corepressor implicated in the onset and progression of rheumatoid arthritis. Biochemistry 2005;44:10570-10582.

6. Wood DD, Moscarello MA. The isolation, characterization, and lipid-aggregating properties of a citrulline containing myelin basic protein. J Biol Chem 1989;264:5121-5127.

7. Kim JK, Mastronardi FG, Wood DD, et al. Multiple sclerosis: an important role for post-translational modifications of myelin basic protein in pathogenesis. Mol Cell Proteomics 2003;2:453-462.

8. Wood DD, Bilbao JM, O'Connors $\mathrm{P}$, et al. Acute multiple sclerosis (Marburg type) is associated with developmentally immature myelin basic protein. Ann Neurol 1996;40:18-24.

9. Brady GW, Fein DB, Wood DD, et al. The interaction of basic protein from normal and multiple sclerosis myelin with phosphatidylglycerol vesicles. FEBS Lett 1981;125:159-160.

10. D'Souza CA, Moscarello MA. Differences in susceptibility of MBP charge isomers to digestion by stromelysin-1 (MMP-3) and release of an immunodominant epitope. Neurochem Res 2006;31:1045-1054.

11. Pritzker LB, Joshi S, Gowan JJ, et al. Deimination of myelin basic protein. 1. Effect of deimination of arginyl residues of myelin basic protein on its structure and susceptibility to digestion by cathepsin D. Biochemistry 2000;39:5374-5381.

12. D'Souza CA, Wood DD, She YM, et al. Autocatalytic cleavage of myelin basic protein: an alternative to molecular mimicry. Biochemistry 2005;44:12905-12913.

13. McLaurin J, Ackerley CA, Moscarello MA. Localization of basic proteins in human myelin. J Neurosci Res 1993;35:618-628.

14. Mastronardi FG, Wood DD, Mei J, et al. Increased citrullination of histone $\mathrm{H} 3$ in multiple sclerosis brain and animal models of demyelination: a role for tumor necrosis factor-induced peptidylarginine deiminase 4 translocation. J Neurosci 2006;26: 11387-11396.
15. Luo $Y$, Arita $K$, Bhatia $M$, et al. Inhibitors and inactivators of protein arginine deiminase 4: functional and structural characterization. Biochemistry 2006:45:11727-11736.

16. Stone EM, Schaller TH, Bianchi $H$, et al. Inactivation of two diverse enzymes in the amidinotransferase superfamily by 2 chloroacetamidine: dimethylargininase and peptidylarginine deiminase. Biochemistry 2005;44:13744-13752.

17. Cheifetz S, Moscarello MA. Effect of bovine basic protein charge microheterogeneity on protein-induced aggregation of unilamellar vesicles containing a mixture of acidic and neutral phospholipids. Biochemistry 1985;24:1909-1914.

18. Raijmakers R, Vogelzangs J, Croxford JL, et al. Citrullination of central nervous system proteins during the development of experimental autoimmune encephalomyelitis. J Comp Neurol 2005;486:243-253.

19. Raijmakers R, Vogelzangs J, Raats J, et al. Experimental autoimmune encephalomyelitis induction in peptidylarginine deiminase 2 knockout mice. J Comp Neurol 2006;498:217-226.

20. Cruz TF, Moscarello MA. Characterization of myelin fractions from human brain white matter. J Neurochem 1985;44:1411-1418.

21. Groome N, Dawkes A, Barry R, et al. New monoclonal antibodies reactive with defined sequential epitopes in human myelin basic protein. J Neuroimmunol 1988;19:305-315.

22. Rus'd AA, Ikejiri $Y$, Ono $H$, et al. Molecular cloning of $C D N A s$ of mouse peptidylarginine deiminase type I, type III and type IV, and the expression pattern of type I in mouse. Eur J Biochem 1999;259: 660-669.

23. Nicholas AP, Sambandam T, Echols JD, et al. Expression of citrullinated proteins in murine experimental autoimmune encephalomyelitis. J Comp Neurol 2005;486:254-266.

24. Peterson GL. A simplification of the protein assay method of Lowry et al which is more generally applicable. Anal Biochem 1977;83:346-356.

25. Pritzker LB, Joshi S, Harauz G, et al. Deimination of myelin basic protein. 2. Effect of methylation of MBP on its deimination by peptidylarginine deiminase. Biochemistry 2000;39:5382-5388.

26. Tarcsa E, Marekov LN, Mei G, et al. Protein unfolding by peptidylarginine deiminase. Substrate specificity and structura relationships of the natural substrates trichohyalin and filaggrin. J Biol Chem 1996;271:30709-30716.

27. Hidaka Y, Hagiwara T, Yamada M. Methylation of the guanidino group of arginine residues prevents citrullination by peptidylarginine deiminase IV. FEBS Lett 2005;579:4088-4092.

28. Klose RJ, Zhang Y. Regulation of histone methylation by demethylimination and demethylation. Nat Rev Mol Cell Biol 2007:8:307-318.

29. Lee YH, Coonrod SA, Kraus WL, et al. Regulation of coactivator complex assembly and function by protein arginine methylation and demethylimination. Proc Natl Acad Sci USA 2005;102:3611-3616.

30. Wang Y, Wysocka J, Sayegh J, et al. Human PAD4 regulates histone arginine methylation levels via demethylimination. Science 2004;306:279-283.

31. Raijmakers R, Zendman AJ, Egberts WV, et al. Methylation of arginine residues interferes with citrullination by peptidylarginine deiminases in vitro. J Mol Biol 2007;367:1118-1129.

32. Moscarello MA, Wood DD, Ackerley C, et al. Myelin in multiple sclerosis is developmentally immature. J Clin Invest 1994;94:146-154.

33. Ludwin SK. The pathogenesis of multiple sclerosis: relating human pathology to experimental studies. J Neuropathol Exp Neurol 2006;65:305-318.

34. Mastronardi FG, Noor A, Wood DD, et al. Peptidyl arginine deiminase 2 $\mathrm{CpG}$ island in multiple sclerosis white matter is hypomethylated. J Neurosci Res 2007;85:2006-2016. 